\title{
Garcilaso y Oliva: dos miradas, dos lecturas de la guerra entre incas $\mathrm{y}$ chancas
}

Clementina Battcock*

Resumen: En este trabajo se analizan de manera comparativa las obras del Inca Garcilaso de la Vega y del jesuita Giovanni Anello Oliva, en particular la versión que brindan sobre la guerra entablada entre incas y chancas. Tradicionalmente a ambos cronistas se les ha atribuido la misma interpretacion de este conflicto y la coincidencia acerca de quién era el Inca que llevó a cabo dicho enfrentamiento y salió victorioso, es decir Viracocha Inca. Por lo tanto, nuestra propuesta radica en revisar cautelosamente estas concordancias en las dos obras y analizar en qué y en dónde difieren sus relatos sobre los hechos trascendentes para la consolidación del Tawantinsuyu en los Andes centrales.

Palabras clave: Chancas, Incas, Guerra, Oráculo, Tawantinsuyu.

ABSTRACT: This paper comparatively analyzes the works of the Inca Garcilaso de la Vega and the Jesuit Giovanni Anello Oliva, particularly the version they provide on the war between the Incas and the Chancas. Traditionally, both writers have been attributed the same interpretation of this conflict and the coincidence about who was the Inca that carried out this conflict and emerged victorious, ie Viracocha Inca. Therefore, our proposal resides in the careful revision of the commonalities in both works and the analysis of where their stories differ on the transcendental facts for the consolidation of the Tawantinsuyu in the central Andes.

Key words: Chancas, Incas, War, Oracle, Tawantinsuyu.

\footnotetext{
Becaria del Programa de Becas Posdoctorales en la unam. Coordinación de Humanidades, Centro de Investigaciones sobre América Latina y el Caribe (cbattcock@yahoo.com.ar).
} 


\section{A MODO DE INTRODUCCIÓN}

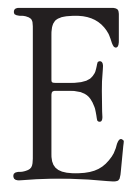

$n$ las principales crónicas andinas se menciona la guerra entre chancas e incas como un parteaguas en la organización política, religiosa, social y económica del Tawantinsuyu. En general aquellas coinciden en señalar la grandeza de Pachacuti, noveno Inca, quien desbarató milagrosamente a los chancas cuando atacaron Cusco, e inició el camino para la construcción del "Imperio" y reconstruyó dicha ciudad que había sido arruinada por las guerras. Es decir, tradicionalmente se ha considerado, según las distintas versiones, que la conformación del Tawantinsuyu y la victoria de Pachacuti, también llamado Viracocha Inca, en la guerra contra los chancas, estaban íntimamente relacionadas. ${ }^{1}$

En este artículo - que constituye un avance de una investigación mayor que está en proceso ${ }^{2}$ se analizan dos versiones sobre la guerra mencionada a partir de los únicos dos cronistas que atribuyen el triunfo a Viracocha Inca, como es el caso del Inca Garcilaso de la Vega y Anello Oliva. ${ }^{3}$ Debemos señalar que ambas obras no sólo difieren en el interés de cada uno de los autores sino, en particular, en la descripción que realizan sobre el tema de la guerra. Por ejemplo, Garcilaso relata de forma extensa, minuciosa y detallista la guerra, mientras que Oliva la narra de manera escueta, casi como un hecho más dentro de la historia del Incario. De esta forma, en el presente estudio se percibirá cómo al realizar un trabajo comparativo de dos obras y de un tema en particular las explicaciones difieren de manera clara y elocuente.

${ }^{1}$ Hidefuji Someda, El imperio de los incas. Imagen del Tabuantinsuyu creada por los cronistas, Lima, Pontificia Universidad Católica del Perú, 2005 (Fondo Editorial), pp. 248 y 249.

${ }^{2}$ Este artículo es producto de la investigación que se lleva a cabo en la estancia posdoctoral titulada: "Un modelo interpretativo de la ascensión al poder de los pueblos hegemónicos en el Nuevo Mundo: las guerras entre los incas y los chancas en el siglo xv", Coordinación de Humanidades, Centro de Investigaciones sobre América Latina y el Caribe, unAm.

3 Inca Garcilaso de la Vega, Comentarios Reales de los Incas [1609], compilado y editado por Rómulo Dueñas Cabezas, Lima, Amc Editores, 2008, 645 pp.; Giovanni Anello Oliva, S. J., Historia del Reino y Provincias del Perú [1631], ed., pról. y notas de Carlos M. Gálvez Peña, Lima, Pontificia Universidad Católica del Perú, 1998 (Fondo Editorial), 386 pp. 
Así, a lo largo del análisis mostraremos cómo si bien estos dos cronistas comparten una visión general sobre la guerra, ambas exposiciones difieren y ponen en evidencia variantes a considerar en nuestro análisis. Por ello, pensamos que confrontar ambas obras nos permite romper el viejo esquema tradicional en el cual los dos cronistas relatan una misma versión sobre los hechos acaecidos en la guerra.

Cabe señalar que diversos especialistas andinos han señalado escuetamente la relevancia de este conflicto; sin embargo, ninguno de ellos se ha detenido a analizar y comparar los distintos relatos que nos brindan las crónicas andinas tempranas y tardías. Sólo unos cuantos autores se han referido al carácter mítico de este hecho y su importancia para la historia del Incario. Así, el artículo publicado por Pierre Duviols ${ }^{4}$ influenció a una generación entera de investigadores y, por lo tanto, sus conclusiones se transformaron con el tiempo en "hechos" irrefutables y en "verdades absolutas". Por ello, hoy en día nos encontramos diferentes posturas en cómo tratar y entender esta guerra. ${ }^{5}$

\section{LOS ANTECEDENTES Y LA GUERRA CONTRA LOS CHANCAS}

El relato que presenta Garcilaso de la Vega sobre la guerra contra los chancas es, sin lugar a dudas, el episodio clave para explicar el ascenso del grupo inca ${ }^{6}$ al

${ }^{4}$ Pierre Duviols, "La guerra entre el Cuzco y los Chanca: ¿historia o mito?", en Revista de la Universidad Complutense, vol. 28, núm. 117, Madrid, 1980, pp. 363-371.

${ }^{5}$ El consenso general que tiene un gran número de investigadores en la materia, se basa en los siguientes argumentos: el primero de ellos es que no es posible reconstruir de las informaciones contendidas en las crónicas, las cuales fueron escritas luego de la conquista española, eventos y procesos históricos que se desarrollaron en la época anterior a dicha conquista, ya que los incas no poseían escritura y no hay fuentes escritas de la época, y por lo tanto no es posible saber en qué medida se trata de información confiable, y en qué medida penetraron dentro del texto ideas, posturas, creencias, instituciones y eventos originados en la cultura europea. El segundo, las versiones de la guerra entre los incas y los chancas que figuran en las distintas crónicas describen todas la misma guerra. Por lo que la mayoría de los investigadores se dedica a interrogar cuál de las crónicas contiene la versión más confiable. El tercero, el relato de la guerra entre incas y chancas es un evento mítico, que no posee base en la realidad.

${ }^{6}$ En este trabajo distinguimos Inca con mayúscula al hacer referencia al gobernante mientras que inca con minúscula al grupo étnico. 
poder de la región y la consolidación de éste en los Andes centrales. De esta forma, dicho autor narra antiguas disputas y tensiones entre ambos grupos. Por ejemplo, durante el reinado del Inca Capac Yupanqui, quinto Inca, se llevan a cabo conquistas sobre los quechuas y la incorporación de este grupo al control del Incario. Así, en el Libro Tercero, capítulo xII, este cronista describe tal hecho y lo interesante es que la sujeción es enmarcada en las tensiones que existen entre los quechuas y los chancas. Al respecto Garcilaso de la Vega indica lo siguiente:

También lo deseábamos por vernos libres de las tiranías y crueldades que las naciones Chanca y Hancohuallo y otras sus comarcas, nos hacen muchos años atrás, desde tiempo de nuestros abuelos y antecesores, que a ellos y a nosotros nos han ganado muchas tierras, y nos hacen grandes sinrazones y nos traen muy oprimidos; por lo cual deseábamos el imperio de los Incas, por vernos libres de tiranos. ${ }^{7}$

De esta forma, podemos pensar que nos hallamos frente a dos grupos, incas y chancas, que compiten por el control del territorio de los grupos que lo ocupan. Indudablemente, no podemos dejar de señalar y considerar que la versión de Garcilaso proviene del grupo dominante inca, como él mismo lo enfatiza a lo largo de toda su obra, y que son sus parientes nobles ${ }^{8}$ quienes le informan sobre el glorioso pasado prehispánico. En contraste, en la obra del padre Oliva, ${ }^{9}$ las guerras contra los chancas se describen casi al pasar, quizá esto responda al interés que tiene dicho jesuita en justificar y legitimar el accionar de su Orden en el virreinato. En este texto, el autor consigna que el nombre del séptimo Inca Yahuar Huacac proviene de ser "prudente". ${ }^{10}$ Este gobernante realizó e inició diversas obras que fueron continuadas por su hijo Viracocha Inca y concluidas por su nieto Pachacuti Inca. ${ }^{11} \mathrm{Al}$ dar estos nombres, llama la atención cómo Oliva explica las diversas interpretaciones o tradi-

\footnotetext{
7 Garcilaso de la Vega, op. cit., Libro Tercero, cap. XII, p. 177.

${ }^{8}$ Por ejemplo, en el Libro Primero, cap. Xv, el autor describe las reuniones que en su niñez y adolescencia vivió y las historias que le fueron narradas por sus parientes maternos, pp. 54-56.

9 Anello Oliva, op. cit. Esta obra fue concluida en 1631 y según Franklin Pease fue escrita con influencias comunes de los años iniciales del siglo xvII, la presencia lascasiana y la información brindada por los quipumayos. Véase al respecto la nota de los editores, p. VII.

${ }^{10}$ Ibid., p. 70.

${ }^{11}$ Ibid., p. 72.
} 
ciones. Entre ellas, lo que indica Catari, cronista de los incas en sus quipus, ${ }^{12}$ es que Viracocha y Pachacuti son los nombres de un solo Inca. De esta forma, en el siguiente apartado de su obra continúa con este problema e indica que diversos historiadores los describieron como dos señores distintos, como Abraham Ortelio en su Texto Universal del Mundo. ${ }^{13}$ Sin embargo, Oliva consideró que lo verdadero era lo planteado por Catari, ${ }^{14}$ mas lo notorio es que a lo largo de su obra los presenta separados. Por lo tanto, considero que esta marcada diferencia que destaca Oliva, indudablemente, manifiesta dos tradiciones sobre el relato de la guerra y que dicho cronista no sólo la hace evidente al lector, sino que demuestra el conocimiento que él posee.

Garcilaso, en el Libro Cuarto, capítulo xv indica cómo Inca Roca conquistó la provincia de Antahuailla ${ }^{15}$ la cual había sido ocupada por los chancas, caracterizados como gente rica y belicosa. Asimismo, señala que éstos decían descender de un "león", ${ }^{16}$ su dios, quien era adorado en sus fiestas por medio de un curioso ritual: los sujetos metían sus cabezas en el cuerpo muerto del animal. ${ }^{17}$

${ }^{12}$ Los quipus eran cordeles con nudos utilizados como un registro. Sobre la relevancia de estos registros véase al respecto el estudio de Gary Urton, Signos del Khipu Inka. Código binario, trad. de Alberto Miori, Cusco, Centro de Estudios Regionales Andinos "Bartolomé de las Casas", 2005, 211 pp.

${ }^{13}$ Anello Oliva, op. cit., p. 72.

${ }^{14}$ Según el estudio introductorio realizado por Carlos M. Gálvez Peña, la crónica se comenzó a escribir hacia 1608 o 1609, ya que posiblemente tomó conocimiento de la obra de Valera. Así, a principios de 1620 Oliva se instala en Chuquisaca y toma contacto con la versión andina de la historia a partir de las relaciones de los quipocamayo. Estas fuentes son interpretaciones escritas del relato de uno de estos especialistas, y posiblemente testigo presencial de algunos hechos de la historia andina, Catari. Véase al respecto, "Prólogo" a Anello Oliva, op. cit., pp. IX-LIX.

${ }^{15}$ Valle enclavado en la sierra central de Perú, en el departamento de Apurimac.

${ }^{16}$ Pensamos que hace referencia al puma, animal que ubica en el género puma junto con el jaguarundi (Puma yagouaroundi), felino nativo de América. Recientes estudios han indicado que el puma y el jaguarundi se encuentran estrechamente relacionados con los modernos guepardos de África y Asia occidental, pero la relación no se ha comprobado. Se ha sugerido que en América el linaje de los guepardos se separó del de los pumas, y luego los primeros reemigraron a Asia y África, mientras que otros estudios indican que los guepardos se dispersaron en el Viejo Mundo independientemente. El esquema de la migración de los pequeños felinos hacia América es, por lo tanto, poco claro. Al respecto véase Tom Zuidema, Reyes y guerreros. Ensayos de cultura andina, comp. Manuel Burga, Lima, FOMCIENCIAs, 1989, pp. 306-331.

${ }^{17}$ Lo curioso de esta descripción es que Garcilaso señala que estos ritos se llevaron a cabo antes y después de la conquista por parte de los incas a lo que agrega: "[...] yo las vi así en 
Lo interesante de este relato es que, seguidamente, informa qué grupos integraban a los chancas: hancohuallu, utunsulla, uramarca, uillca y otros. Éstos provenían de distintos orígenes; sin embargo, todos vinieron de "Tejas" [sic] tierras y fueron conquistando regiones hasta asentarse en la provincia de Antahuailla. Es decir, estos grupos no sólo compartían con los incas la práctica de conquista, sino que al igual que ellos eran, quizá, hablantes quechuas. De esta forma, el autor conecta y justifica de manera directa los hechos narrados en el Libro Tercero sobre la "bienvenida" que reciben los incas de los quechuas.

Asimismo, el relato es complementado con la actitud de Inca Roca, quien está informado de los hechos y de los sufrimientos de los quechuas en manos de los chancas. Los incas y, sobre todo, la figura del gobernante aparecen como los salvadores y rescatadores de los quechuas. Por lo tanto, inferimos que nos hallamos ante un desplazamiento de poder a través de una política de conquista y que Garcilaso, en su texto, explica este movimiento por medio de una estructura simple y lineal: entre buenos y malos, vale decir, entre incas y chancas. A la vez, pensamos que esta estructura podría ser entendida como expresión de relaciones entre parejas vinculadas o conjuntos diádicos, que se hallan en una conexión de oposición binaria asimétrica entre sí.

Al llegar a los límites de Antahuailla, el Inca envía a los chancas los requerimientos para que se sometan a su poder o se les declarará la guerra. Los grupos chancas, al recibir este mensaje, se reúnen y se dividen en dos posiciones. Unos planteaban sujetarse al Inca, mientras que los descendientes del "león" se oponían debido a su carácter de conquistadores. Así, estuvieron varios días, hasta que el Inca envió a un mensajero con el último ofrecimiento. Al ver que los incas no eran el único grupo que los enfrentaba, ya que el ejército estaba compuesto por quechuas y otros pueblos, los chancas decidieron ceder e incorporarse a los territorios y grupos conquistados. Sin embargo, el relato deja de manifiesto que dicha actitud se debió al "temor a las armas", aunque se mantuvo latente el rechazo a incorporarse al control del Incario.

las fiestas del Santísimo Sacramento, en el Cuzco." Garcilaso, op. cit., Libro Cuarto, cap. XV, p. 236. 
Seguidamente, Inca Roca prosiguió con sus conquistas y avanzó sobre territorios del grupo chanca, el primero que opuso resistencia fue Uramarca, después Hancohuallu y Uillca. Aquí nuevamente el relato señala el enfrentamiento y su posterior sujeción a Inca Roca. ${ }^{18}$

En el capítulo xx se narra la muerte de este Inca, a quien le sucedió Yáhuar Huácac. Es interesante notar cómo la figura de este último Inca es medular en la construcción y legitimación del siguiente gobernante, Viracocha Inca. Entre estos dos personajes se observa un esquema de enfrentamiento entre padre e hijo. Cada uno de ellos representa una actitud política diferente y opuesta, por ejemplo el padre es pasivo y no busca la confrontación, mientras que su hijo es activo y con características guerreras. Por lo cual, proponemos que en dicho esquema se plasmarían dos modelos políticos diferentes. El primero, representado por el padre, el cual no busca enfrentamiento, se ajusta y adapta a la sujeción chanca, es decir, no conquista. El segundo, simbolizado por el hijo, el cual conquista, expande y lleva a cabo la guerra.

De esta forma, se narra que el hijo "heredero" de Yáhuar Huácac, de quien aún no se sabe el nombre pero que después se denominará Viracocha Inca, es desterrado por su padre a partir de una conducta no adecuada:

[...] desde niño se había mostrado mal acondicionado, porque maltrataba [a] los muchachos que de su edad con él andaban y mostraba indicios de aspereza y crueldad, y aunque el Inca hacía diligencias para corregirle y esperaba que con la edad, cobrando más juicio, iría perdiendo la braveza de su mala condición, parecía salirle vana esta confianza, porque con la edad antes crecía que menguaba la ferocidad de su ánimo. ${ }^{19}$

${ }^{18}$ Es interesante señalar que sobre este enfrentamiento y posterior sujeción inca, el autor enfatizó que en estas provincias chancas se tenía por costumbre el sacrificio de niños a sus dioses, lo cual no era aceptado por los incas quienes los obligaron a adoptar el culto al Sol. Ibid., Libro Cuarto, cap. XV, p. 238.

${ }^{19}$ Ibid., cap. xx, p. 247. 
Así Yáguar Huácac decidió actuar al respecto y:

[...] acordó desfavorecerlo del todo y apartarlo de sí con propósito, si no aprovechaba el remedio del disfavor para enmendar la condición, de desheredarlo y elegir otro de sus hijos para heredero, que fuese de la condición de sus mayores. [... mandó echarlo de su casa y de la corte, siendo ya el príncipe de diez y nueve años, y que lo llevasen poco más de una legua al levante de la ciudad, a unas grandes y hermosas dehesas que llaman Chita [... . ${ }^{20}$

Años más tarde, el "príncipe" retorna a ver a su padre para informarle sobre la visión o sueño que tuvo. Sin embargo, el encuentro entre ambos no es el más feliz, su padre lo rechaza y el "heredero" le informa que no vino por su voluntad sino porque lo había enviado "otro tan gran Inca como él." De esta forma, se describe cómo a este "príncipe" - que se encontraba recostado sobre los pastos de Chita, no sabe si despierto o dormido $-{ }^{21}$ se le apareció el dios Viracocha, quien se identificó como tal y le previno de los levantamientos que se estaban organizando en las provincias del Chinchasuyu y en otras y que planeaban atacar el Cusco. Viracocha se dirigió al "príncipe" y le dijo:

Y en particular te digo a ti que en cualquiera adversidad que te suceda no temas que yo te falte, que en todas te socorreré como a mi carne y sangre. Por lo tanto no dejes de acometer cualquiera hazaña, por grande que sea, que convenga a la majestad de tu sangre y a la grandeza del Imperio, que yo seré siempre en tu favor y amparo y te buscaré los socorros que hubieres menester. ${ }^{22}$

Sin embargo, su padre no quiso creer tal relato y lo calificó de "loco soberbio" y le ordenó que regresara a Chita y que no volviera jamás. Al respecto quizá podríamos interpretar este rechazo a partir de lo señalado por Fernández Juárez:

${ }^{20}$ Ibid., cap. Xx, p. 248.

${ }^{21}$ Según Marco Curatola Petrocchi, "La buaca se comunicaba con ellos hablándoles o a través de sueños." Véase al respecto Marco Curatola Petrocchi, "La función de los oráculos en el Imperio inca”, en Marco Curatola Petrocchi y Mariusz S. Ziólkowski [eds.], Adivinación y oráculos en el mundo andino antiguo, Lima, Instituto Francés de Estudios Andinos/Pontificia Universidad Católica del Perú, 2008 (Fondo Editorial), p. 28.

${ }^{22}$ Garcilaso, op. cit., Libro Cuarto, cap. XXI, p. 250. 
"Aquellos personajes que han sido vistos en el trance onírico de la visión, no pueden ser percibidos por el ojo humano de los no iniciados."23

Los otros incas que escucharon el relato le aconsejaron a Yáhuar Huácac que prestara atención a ese sueño, ya que era un aviso de Viracocha. Sin embargo, el Inca no hizo caso y les ordenó guardar silencio. Llama la atención dicho rechazo por parte del Inca, ya que tal como lo indica Marco Curatola Petrocchi:

[...] hay que recordar que, con toda probabilidad, para los incas el ser sobrenatural llamado Viracocha no era más que una de las manifestaciones del dios Sol, siendo justamente su figura estrechamente relacionada con el astro rey al momento de su máximo auge, es decir, al tiempo del solsticio de verano. ${ }^{24}$

Sobre la preeminencia que tienen los sueños para esta sociedad, Garcilaso describe que lo que soñaba el Inca, el heredero o el "Sumo sacerdote" es de vital relevancia ya que ellos eran considerados "dioses y oráculos mayores". Podría pensarse que la escena del sueño opera como un discurso legitimador a partir de la puesta en imágenes de un libreto donde lo que se juega es el orden de la transmisión de un poder por la vía del nombre, allí precisamente donde esta nominación por parte de Yáhuar Huácac hacia su hijo se presenta como desfalleciente.

Por lo tanto, considero pertinente plantear ciertas interrogaciones, ¿es casual que en estos momentos previos al conflicto con los chancas el "heredero" no tenga nombre? ¿Por qué siempre es señalado por su padre como "loco y soberbio"? ¿Qué efectos tiene esta nominación en la cual "loco", "soberbio" se inscriben como sustitución de la falta de un nombre propio?

Esto nos lleva a preguntarnos ipor qué, entonces, Yáhuar Huácac no prestó atención al sueño de su hijo? O si lo que debemos entender es que este relato evidencia la tensión entre dos modelos políticos incas, y por eso el especial énfasis en señalar lo que le dice Viracocha al "heredero". Por otra parte, es notorio

${ }^{23}$ Gerardo Fernández Juárez, Entre la repugnancia y la seducción. Ofrendas complejas en los Andes del Sur, Cusco, Centro de Estudios Regionales Andinos "Bartolomé de las Casas", 1997, p. 86.

${ }^{24}$ Véase al respecto Curatola Petrocchi, op. cit., p. 26. 
que el dios Viracocha no se dirigió directamente al Inca. Pensamos que quizá el contexto que se describe está representando un medio a través del cual las distintas facciones podían expresar al Inca su opinión, sus aspiraciones y hasta su disenso, sin que esto significara un desafío o cuestionamiento directo a la persona real del Inca. De todas formas debemos considerar el problema sucesorio, contexto ante el cual evidentemente estamos presentes. ${ }^{25}$

Asimismo, el estudio de Fernández Juárez sobre la sociedad contemporánea aymara nos permite vincular los hechos antes descritos con algunos datos etnográficos sobre los especiales rituales aymaras y las formas peculiares que adquiere la iniciación ritual. Así, una de las importantes vías para acceder a la autoridad ceremonial, es decir a Viracocha, es a través de los sueños. De esta forma las imágenes oníricas posibilitan el contacto del aspirante con los detentadores del poder ceremonial, que se aparecen en los sueños y hablan con el candidato, invistiéndole de la autoridad necesaria para el ejercicio de su labor. A la vez, dicho autor nos indica que el sueño reproduce los términos básicos de un viaje de iniciación chamánico, en el que el individuo sufre un desplazamiento espacial y temporal, narra los acontecimientos involucrados en un aura de visión distorsionada, como corresponde a los sueños y sus imágenes. ${ }^{26}$

Garcilaso, en el capítulo xxiII, narra que después de tres meses del encuentro con su padre, Viracocha Inca, es decir, el "príncipe" heredero, ${ }^{27}$ se enteró de los levantamientos en las provincias del Chinchasuyu y de los grupos chanca, uramaraca, uilca, utunsulla, hancohuallu y otros, cuyos ejércitos avanzaban hacia el Cusco. El autor señala que dicho levantamiento se debió a que estos pueblos sojuzgados vieron que Yáhuar Huácac era "poco belicoso" y que a su vez este Inca

${ }^{25}$ En relación al problema sucesorio existen dos propuestas sobre cómo entender este complejo sistema. Por un lado, la que plantea María Rostworowski con el correinado; y por el otro Franklin Pease quien señala el dualismo en el poder. Véase al respecto María Rostworowski, Pachacutec Inca Yupanqui, traductor, Lima, Instituto de Estudios Peruanos, 1953, y Franklin Pease, Los últimos incas del Cusco, Madrid, Alianza América, 1991, pp. 95-98.

${ }^{26}$ Sobre las iniciaciones chamánicas véase Mircea Eliade, El chamanismo y las técnicas arcaicas del éxtasis, 2a ed., México, FCE, 1986, 484 pp., y del mismo autor Iniciaciones místicas, Madrid, Taurus, 1989, $232 \mathrm{pp}$.

${ }^{27}$ Garcilaso, op. cit., indica que Viracocha Inca: "[... ] le llaman los suyos de aquí en adelante, por el fantasma que vio"., p. 252. 
tenía fricciones con su hijo. Así, consideraron que era el momento indicado para rebelarse y concertar alianzas con otros pueblos que se hallaban en su misma situación. Dicha alianza se basó en la promesa de dividir parte de la ganancia que se obtendría tras derrocar a los incas al tomar el Cusco. Los dirigentes fueron tres curacas chancas: Hancohuallu, quien fue elegido como capitán general, Túmay Huaraca y Astu Huarca, estos dos últimos hermanos y deudos del primero. Por otro lado, Yáhuar Huácac no llegó a concertar alianzas y consideró pertinente escapar hacia el Collasuyu. De esta forma, se retiró y abandonó el Cusco con algunos incas hacia Muina. Así, el Cusco quedó desamparado, pero Viracocha Inca al enterarse de lo sucedido y de la huida de su padre va detrás suyo y lo cuestiona duramente sobre su actuación. Al respecto, pensamos que en este capítulo se puede observar no sólo la transición política que se llevó a cabo, sino los dos modelos antagónicos que se enfrentaron, representados por el padre y el hijo, como antes planteamos, y que el nuevo modelo se implementó y se impuso en el contexto de una guerra. Igualmente, Garcilaso nos describe que tras el reclamo de Viracocha Inca a su padre, "los Incas de sangre real" se vuelven con aquel para la defensa del Cusco y que, en cambio, quedan con su padre los "viejos inútiles." ${ }^{28}$

En el Libro Quinto, capítulo xvi, Garcilaso retoma la historia sobre el enfrentamiento contra los chancas. Es interesante notar que, en el relato, tras las malas decisiones del gobernante cobarde, los incas no establecieron alianzas ni tuvieron la ayuda de otros grupos y, por ello, el Cusco se encontró desamparado y con pocas posibilidades de sobrevivir tras el ataque de los chancas y sus aliados. De esta manera ya en este Libro, Viracocha Inca adquiere todas las características de un líder guerrero, y así comienzan a socorrerle diferentes grupos del Contisuyu, como por ejemplo, quechuas, cotapampas, cotaneras y aymaras. ${ }^{29} \mathrm{~A}$ la vez, este gobernante atribuyó este auxilio y la futura victoria a las palabras e intervención del "fantasma Viracocha". Así, este gobernante es presentado como un re-

${ }^{28}$ Ibid., Libro Cuarto, cap. XXIv, p. 255.

${ }^{29} \mathrm{Al}$ respecto, Garcilaso señala que: "El, príncipe los recibió con mucho agradecimiento del amor que a su Inca tenían, hizo grandes favores y regalos a los curacas de cada nación y a todos los demás capitanes y soldados, loando su lealtad y ofreciendo para adelante el galardón de aquel servicio tan señalado." Ibid., Libro Cuarto, cap. XVII, p. 295. 
novador en lo militar y en lo religioso, ya que precisamente su vinculación con la deidad le permite adquirir una cualidad arquetípica y un carácter sagrado. ${ }^{30}$

Los preparativos para la guerra se inician y los chancas siguen avanzando hasta que llegan todos a Sacsahuana donde se encontraba Viracocha Inca y su ejército, quien envía una comitiva de paz a los chancas. Sin embargo, éstos evalúan que la forma de actuar de Yáhuar Huácac se podía aplicar a su hijo y rechazan el ofrecimiento. A la postre, Viracocha Inca envía una segunda comitiva, la cual de nuevo es rechazada e inevitablemente se llega al enfrentamiento. El Inca Viracocha es quien lideraba la lucha desde el frente. La duración de la batalla se puede entender a través de dos etapas: la primera, donde ambos bandos estaban parejos; y la segunda, a partir del apoyo que les llegó a los incas, con lo que lograron la victoria final. De esta forma, observamos que el auxilio que reciben los incas de diferentes pueblos vecinos, al enterarse de que el Inca Viracocha estaba defendiendo Cusco y acuden a socorrerlo, produce el desenlace final. Sobre este particular suceso nos dice Garcilaso que los incas construyeron una "fábula" para engrandecer tales eventos. Específicamente, el cronista hace referencia al relato de que, en esta guerra, los incas fueron ayudados por las piedras y las matas de aquellos campos que se convirtieron en hombres-guerreros, ya que el Sol y el dios Viracocha así lo dispusieron. Pensamos que aquí se está haciendo referencia al poder que tenía el Inca al lograr dialogar con las huacas, es decir, todo aquello que contenía en sí lo sagrado, que en este caso son las piedras. Esta práctica era considerada una capacidad divina del gobernante y parece que el primer Inca que la inicia es precisamente Viracocha Inca. ${ }^{31}$

En torno a los hechos y reconstrucción de la famosa batalla y la intervención de las piedras, Garcilaso señala que se basa en el Libro Segundo de la obra República de las Indias Occidentales del padre fray Jerónimo Román. ${ }^{32}$ También es claro que consulta, no sólo para este libro, sino en toda la obra, el texto del

\footnotetext{
${ }^{30}$ Pease, op. cit., p. 23.

${ }^{31}$ Clementina Battcock, "Un oráculo para lo que de alli adelante quisiete ordenar. La figura de Viracocha Inca en la obra de Garcilaso de la Vega", ponencia presentada en el simposio "Las dimensiones simbólicas de las prácticas chamánicas entre los pueblos originarios de América", en el XIII Congreso Latinoamericano sobre religión y etnicidad, Granada, España,13 de julio, 2010. ${ }^{32}$ Ibid., Libro Quinto, cap. XVIII, p. 297.
} 
padre Acosta, ${ }^{33}$ y lo más inquietante es que si bien consulta y compara estas dos obras, algunas cosas toma de ellas y otras no. Por ejemplo, tanto Román como Acosta no llaman al "príncipe heredero" Viracocha sino Pachacuti Inga Yupanqui. Para Rostworowski, ${ }^{34}$ el que Garcilaso atribuyera la victoria a Viracocha Inca, se debió al origen de la madre del cronista, la cual provenía de la panaca llamada Capac Ayllu, y la cual estaba enfrentada a la panaca de Hatun Ayllu de Pachacuti Inca. ${ }^{35}$ Consideramos que este señalamiento que realiza la autora es relevante para nuestro análisis, ya que considera que no existía en el Cusco una sola versión de estos hechos, sino que había distintas interpretaciones según los distintos grupos de poder, es decir, las panacas, las cuales reproducían, según su propio interés, y legitimaban su lugar en el antiguo orden incaico.

Sobre la extensión de la batalla dice Garcilaso que duró ocho horas y que fue sumamente sangrienta, a tal grado que el espacio donde se enfrentaron se llamó Yaguar Pampa, que quiere decir "campo de sangre". Tras la derrota chanca, quedaron cautivos los líderes Hancohuallu y sus dos maeses de campo, quienes fueron cuidados por orden del Inca Viracocha.

${ }^{33}$ Según lo citado por Garcilaso sobre el texto de Acosta, hemos seleccionado esta otra versión sobre los hechos: "Dice, pues, Su Paternidad lo que se sigue, que es sacado a la letra," Libro Sexto, capítulo veintiuno: "Pachacuti Inga Yupanqui reinó sesenta años y conquistó mucho. El principio de las victorias fue que un hermano mayor suyo, que tenía el señorío en vida de su padre y con su voluntad administraba la guerra, fue desbaratado en la batalla que tuvo con los Changas, que es la nación que poseía el valle de Andaguailas, que está obra de treinta leguas del Cuzco, camino de Lima; y así desbaratado, se retiró con poca gente. Visto esto, el hermano menor, Inga Yupanqui, para hacerse señor, inventó y dijo que, estando él solo y muy acongojado, le había hablado el Viracocha creador, y quejándosele que siendo él señor universal y criador de todo, y habiendo él hecho el cielo y el Sol y el mundo y los hombres, y estando todo debajo de su poder, no le daban la obediencia debida, antes hacían veneración al Sol y al trueno y a la tierra y otras cosas [... le llamaban Viracocha Pachayacháchic [... . Y Y desde aquella victoria estatuyó que el Viracocha fuese tenido por señor universal [...]. Habida, pues la victoria de los Changas, declaró a sus soldados que no habían sido ellos los que habían vencido, sino ciertos hombres barbudos que el Viracocha le había envido, y que nadie pudo verlos sino él, y que éstos se habían después convertido en piedras que convenía buscarlos, que él los conocería. Y así juntó de los montes gran suma de piedras, que él escogió y puso por guacas [...]", en ibid., Libro Quinto, cap. xviII, pp. 298 y 299.

${ }^{34}$ Rostworowski, op. cit., pp. 26-30.

${ }^{35}$ La panaca era un grupo del linaje de la "dinastía real", o ayllu, creado por cada Inca. 
Enseguida él envió a tres mensajeros para que notificaran la victoria, primero a la Casa del Sol, segundo al Acllawasi y luego a su padre a quien le informó sobre la victoria y le ordenó que no se moviera de donde se encontraba. Posteriormente, Viracocha Inca emprendió una serie de visitas a diversos lugares, como Antahuailla, Cusco, donde fue recibido por su madre, la Coya Mama Chicya y otras mujeres de la realeza inca, después visitó a las "vírgenes mujeres del Sol" y, por último, salió hacia Muina donde se hallaba su padre. El encuentro entre padre e hijo fue nuevamente tenso, y la decisión de quién debía gobernar fue concertada en una charla secreta en la que se resolvió que el Inca Yáhuar Huá$\mathrm{Cac}^{36}$ no regresaría al Cusco por haberla abandonado. Así, Viracocha Inca tomó posesión de la borla colorada y dejó la borla amarilla. ${ }^{37}$ Clara manifestación de su nueva autoridad y estatus.

Tras el relato de la guerra, en el capítulo xxi del Libro Quinto, Garcilaso señala por qué el "príncipe" se llamó Viracocha Inca o Inca Viracocha, quien a partir de esta guerra se convirtió en un oráculo. ${ }^{38}$ Este dato que nos brinda el cronista es elocuente, sin lugar a dudas, puesto que no sólo nos indica cuándo se convierte en oráculo - tras la guerra-sino evidencia que, en este contexto, se legitima el poder del nuevo Inca. Al respecto, Silvia Limón Olvera ha señalado que los oráculos ocupaban un lugar destacado en la religión andina, ya que constituían un medio de comunicación con lo sagrado que implicaba que la divinidad se manifestara de manera verbal con algún individuo. ${ }^{39}$

\footnotetext{
${ }^{36}$ Sobre el nombre de este Inca, Garcilaso indica que su nacimiento tuvo ciertas particularidades, como haber llorado sangre, y que debido a estas características recibió ese nombre que pronosticaría su mal futuro.

${ }^{37}$ Se está haciendo referencia a la mascaypacha, es decir, la banda de tejido que llevaba el Inca como signo de su cargo.

${ }^{38} \mathrm{Al}$ respecto, Garcilaso señala que: "[...] hecho un oráculo para lo que de allí adelante quisiete ordenar y mandar a los indios". Ibid., Libro Quinto, cap. xxI, pp. 306 y 307.

${ }^{39}$ Silvia Limón Olvera, "Oráculos y adivinación en los Andes: su significado político religioso", en Revista Mitológicas, vol. I, Buenos Aires, Centro Argentino de Etnología Americana, 2005, pp. 9-24.
} 


\section{LAS CONSECUENCIAS DE LA VICTORIA INCA: CAMBIOS Y TRANSFORMACIONES EN LOS}

\section{ANDES CENTRALES}

Tras la victoria contra los chancas, el Inca Viracocha realiza varios actos significativos. Entre ellos podemos citar: la construcción de un templo, en el pueblo de Cacha, en honor a su "tío"; la realización de una estatua; una pintura con dos cóndores que gratifica a los aliados quechuas, en especial a Cotapampa y Cotanera ${ }^{40}$ y eligió cuatro incas por consejeros. Posteriormente, se trasladó a la provincia de Antahuailla y les regaló vestidos y otros objetos a los principales chancas. Visitó dos fortalezas, Challcumarca y Suramarca, antiguamente chancas, promulgó leyes, envió a las provincias chancas grupos quechuas de población aliados a incas y designó por "caudillos" en esas tierras a Incas de privilegio, proyectó edificios importantes en el valle de Yucay y Tampu y amplió la Casa del Sol en Cusco.

La figura de este Inca surge como pronóstico, como oráculo, pues a través de sus sueños predice lo que va a suceder ${ }^{41}$ porque ya lo ha "visto" y sabe cómo desenvolverse, por lo tanto expresa un "saber hacer" que lo autoriza y capacita en el ejercicio del poder. Así, el ver mientras se duerme es también una singularidad exaltada por la explicación chamánica ritual. Marca de la omnipotencia del pensamiento, donde se resalta no sólo un lugar en la cadena generacional sino, también, un interesante entramado entre la escena del sueño y la de la vida política y social.

En el Libro Quinto, capítulo xxvi, Garcilaso habla de Hancohuallu, líder chanca que fue apresado tras la derrota. Refiere que estuvo "preso" de nueve a diez años y que, si bien fue el perdedor en la contienda, los incas no le quitaron sus derechos en su jurisdicción porque lo consideraban un "gran señor" desde antes de la guerra. ${ }^{42}$ Sin embargo, Hancohuallu y otros chancas decidieron marcharse hacia las montañas de los Antis. ${ }^{43}$ En este contexto, resulta sumamente curiosa la nominación de este

${ }^{40}$ Garcilaso, op. cit., Libro Quinto, cap. XXIII, p. 311. Es interesante que en el Libro Quinto, cap. XXv, el autor vuelve a enfatizar que los quechuas fueron aliados de los incas en la guerra contra los chancas y por eso los premia con favores, p. 314.

${ }^{41}$ En relación con todos estos sucesos véase Garcilaso, op. cit., Libro Quinto, caps. xXII a XXVIII, pp. 307-322.

${ }^{42}$ Ibid., Libro Quinto, cap. xxvI, p. 317.

${ }^{43}$ Ibid., Libro Quinto, cap. XxVI, pp. 317-319. 
capítulo como: "Un segundo motín" el cual no está registrado en el texto, es decir, el título de este capítulo no corresponde con lo que se narra a lo largo del mismo.

\section{Sobre El NOMBRe PaChaCUTEC}

En el Libro Quinto, capítulo xxviII de los Comentarios Reales de Garcilaso, se relata que del Inca Viracocha y de la Coya Mama Runtu nace Titu Manco Capac, pero que el Inca ordena en su testamento que se llame Pachacutec. Es sugestiva la explicación de Garcilaso, quien expone que el Inca Viracocha debió llamarse Pachacutec debido a que produjo un cambio, una transformación a partir de la guerra contra los chancas y de la huida de su padre. Sin embargo, no pudo llamarse así ya que desde que apareció el "fantasma" Viracocha, todos lo conocían así. Por eso, su hijo heredero debía llamarse Pachacutec, pues su nombre recordaba la hazaña de su padre. Así, indica Garcilaso que Pachacutec significa: "[... ] el que vuelve, o el que trastorna o trueca el mundo; dicen por vía de refrán pácham cutini; quiere decir el mundo se trueca, y por la mayor parte lo dicen cuando las cosas grandes se truecan de bien en mal [...]." ${ }^{\prime 4}$

En la obra del jesuita Anello Oliva se relata que el octavo Inca, Topa Inca o Viracocha, realizó diversas conquistas en provincias que no estaban "muy sujetas." Por ello, conformó un ejército y se enfrentó a los chancas hancouallos que se "avían puesto en armas. "5 Apresó a Tomaiguanca y Astoguanca y partió contra los soras y los lucanas, tomó fortalezas como la de Challcomarca y Soramarca y regresó a Cusco llevando consigo a Hancouallo. Ya en esta ciudad despachó a Capac Yupanqui, hermano y capitán del ejército, para que sojuzgase a los ancaraes, chocorbos, guancas, yauyos, tarmas, atavillas, gayllas, guanuco, conchuco.

Posteriormente, el Inca se lanzó a conquistar el "Reyno de Chile" y de camino visitó el templo de Titicaca, donde ordenó levantar edificios en Copacabana y mandó llevar desde Cusco a mamaconas y nustas para que sirvieran en ese templo. Asimismo, dispuso en los caminos la construcción de puentes, pozas de agua y tambos con provisiones para el ejército. ${ }^{46}$

\footnotetext{
${ }^{44}$ Garcilaso, op. cit., Libro Quinto, cap. xxvIII, p. 321.

${ }^{45}$ Anello Oliva, op. cit., p. 73.

${ }^{46}$ Ibid., p. 74.
} 
En relación con el noveno Inca (Pachacuti), Oliva retoma las dos opiniones que antes esbocé en el inicio de este artículo. La primera de ellas es la que sostiene Catari quien propone que Pachacuti y Viracocha Inca eran una misma persona y que le agregaron el primer nombre: "[...] porque fuese gran guerrero que casi nunca parava ocupándose de contino en nuevas empresas, le llamaron Pachacuti, que quiere decir, el que trastorna el mundo, y da buelta en todo él." ${ }^{\text {‘7 }}$

La segunda opinión que el cronista trae es la de Abraham Ortelio ${ }^{48}$ y la del Inca Garcilaso, la cual Oliva considera la más probable, Pachacuti es hijo del Inca Viracocha y al igual que su padre emprende nuevas conquistas por distintas provincias. ${ }^{49}$ Es interesante señalar que Oliva dice seguir a Catari en cuanto a las dos opiniones que en el texto indica primeramente, pero como observamos en este último párrafo aquí dice seguir y compartir la opinión de que son dos personas distintas.

\section{ALGUNAS CONSIDERACIONES FINALES}

El episodio de la guerra contra los chancas en la historia de los incas, resulta un momento clave para explicar el surgimiento del Tawantinsuyu. En las dos obras aquí examinadas, hemos observado la reconstrucción que se realiza de este singular hecho a través de la carga simbólica que contiene la guerra, así como el o los significados que subyacen en el relato.

A la vez, es notorio que esta guerra se contextualice en momentos de tensiones y de acomodamientos políticos en los Andes centrales, y tras la resolución del conflicto surja el Tawantinsuyu. Como señalamos a lo largo de este trabajo, los grupos incas y chancas comparten sus políticas de conquistas expansivas y compiten por apoderarse de un territorio, el cual es claramente quechua.

De esta forma, el éxito de la guerra y la asunción del Inca Viracocha están íntimamente relacionados, es decir, aparece como una unidad explicativa que permite marcar un antes y un después en la estructura general de los relatos de la historia inca.

Si bien los dos autores analizados coinciden en señalar la diferencia entre Viracocha Inca y Pachacutec, sus textos responden a distintas preocupaciones

${ }^{47}$ Loc. cit.

${ }^{48}$ Nuevamente cita la obra de este autor Teatro Universal.

${ }^{49}$ Ibid., pp. 74-77. 
e intereses. Pensamos que cada autor llega desde distintas perspectivas (miradas y enfoques) a una casi misma versión de la guerra. Por ejemplo, Oliva parte de un análisis comparativo, realiza una crítica de fuentes, las coteja y, al final, se decide por la que Viracocha Inca y Pachacutec son dos personas distintas. Evidentemente, este cronista se percata de las distintas tradiciones que existen y las construcciones de los hechos que a partir de ellas se realizan.

Por otra parte, en la obra de Garcilaso no se evidencia que haya otras tradiciones en torno a la guerra, sino que podemos indicar que para él sólo hay una, la que relata con lujo de detalles con base en lo transmitido por sus familiares, es decir, la versión que tienen ellos al pertenecer a la panaca de Capac Ayllu, y lo que otras obras le permiten reconstruir. Así, para este cronista es sumamente importante la guerra, lo podemos ver por ejemplo, en el Libro Nono, capítulo xxxvis, cuando relata los conflictos entre Huáscar y Atahualpa, y vuelve a hacer referencia a la famosa guerra partiendo del nombre que se le puso al sitio del enfrentamiento: Yaguarpampa..$^{50}$

Por último, en este trabajo se propuso analizar de manera comparativa las versiones de estos cronistas, las cuales siempre se han indicado como similares pero, como lo hemos demostrado no lo son, por lo que hay que ser cuidadosos con este tipo de afirmaciones. Así, a lo largo de este breve estudio observamos no sólo las variantes, sino también las relaciones de filiación entre un texto y el otro, y las fuentes de inspiración originarias. Por último, según el contexto de las interpretaciones que hemos analizado, la guerra contra los chancas es, como ya lo señaló Tom Zuidema, ${ }^{51}$ un mito de carácter político y a la vez una respuesta a la necesidad de construir una guerra ejemplar en los rituales de iniciación.

Recibido: 28 de junio, 2010. Aceptado: 8 de noviembre, 2010.

${ }^{50}$ Garcilaso de la Vega, op. cit., Libro Nono, cap. xxxvII, p. 636.

${ }^{51}$ Zuidema, op. cit., p. 332. 